\title{
The Smart Door: An Example of System Engineering in Building Industry
}

\author{
Gauthier Fanmuy, Arnaud Durantin, Hugo Messicat \\ and Bertrand Faure
}

\begin{abstract}
Systems Engineering is now becoming mandatory to master complexity but also to develop innovative systems. Application of Systems Engineering requires the use of a methodology upon tool set. This paper is about the application of a Systems Engineering methodology from CESAMES on a small but complex system: an automatic sliding door in a building. We all experienced it: automatic doors have tendency to open inadvertently for example when pedestrian just walks by with no intention to enter the room. This is due to an old technological design: easiest way to decide to open the door is to detect a person in a trigger zone. With a system approach, the door could be nicely improved with great potential developments. This document explains how, and the method used to do it.
\end{abstract}

G. Fanmuy $(\bowtie) \cdot$ A. Durantin $\cdot$ H. Messicat · B. Faure Dassault Systèmes, 10 Rue Marcel Dassault, Vélizy Villacoublay 78140, France e-mail: G4Y@3ds.com
A. Durantin
e-mail: ADN3@3ds.com
H. Messicat
e-mail: HMT1@3ds.com
B. Faure
e-mail: BFU@3ds.com 